\title{
Pattern of Ocular Morbidity in School Going Children
}

\author{
Alok Ranjan¹, Prashanthkumar Narayan Achar ${ }^{2}$, Perwez Khan ${ }^{3}$, Mohammed Hafeez ${ }^{4}$ \\ ${ }^{1}$ GSVM Medical College, Kanpur, Uttar Pradesh, India. ${ }^{2}$ Srinivas Institution of Medical \\ Sciences \& RC, Mukka, Surathkal, Mangalore, Karnataka, India. ${ }^{3}$ GSVM Medical College, \\ Kanpur, Uttar Pradesh, India. ${ }^{4}$ KIMS, Karwar, Karnataka, India.
}

\section{ABSTRACT}

\section{BACKGROUND}

We wanted to determine the prevalence of ocular morbidity among school going children between ages of 6 and 16 yrs. in public schools of urban and rural areas of Kanpur city and study its pattern.

\section{METHODS}

A cross-sectional prospective study was done among a total of 2105 school going children (rural - 956 and urban -1149), 6-16 years of age in rural and urban areas of Kanpur city. A comprehensive ocular examination was done with the help of torch light, slit lamp and $+90 \mathrm{D}$ and direct ophthalmoscope to examine the anterior \& posterior segment pathologies.

\section{RESULTS}

Ocular morbidity in the rural population was 817 (no. of diagnosed cases) of which $43.30 \%$ were in rural areas of which $63.52 \%$ were males. $35.07 \%$ were in urban areas of which $57.81 \%$ were males. The most common type of ocular morbidity in rural population was refractive error (15.9\%), followed by vitamin A deficiency (12.86\%), blepharitis (5.43\%), squint (3.66\%), amblyopia $(2.87 \%)$, stye $(2.40 \%)$, ptosis $(1.67 \%)$, colour blindness $(1.15 \%)$, and posterior segment pathologies $(0.19$ $\%)$.in urban areas, the most common cause was refractive error (26.19\%), followed by squint (2.78\%), amblyopia (1.91\%), vitamin A deficiency (1.91\%), blepharitis (1.83\%), colour blindness $(1.21 \%)$, stye $(0.70 \%)$, ptosis $(0.35 \%)$ and posterior segment pathologies $(0.08 \%)$. The difference was statistically extremely significant with $\mathrm{p}=0.0001$.

\section{CONCLUSIONS}

Refractive error was the most common ocular morbidity in both urban and rural areas, but Vitamin A deficiency and blepharitis were more common in rural areas. In rural areas malnutrition seems to be the major cause of ocular morbidity while more use of gadgets and less outdoor activity seems to play vital role in urban areas.

\section{KEY WORDS}

Ocular Morbidity, Refractory Errors, Squint, Amblyopia, Vit. A Deficiency
Corresponding Author:

Dr. Prashanthkumar Narayan Achar.

Srinivas Institute of Medical Sciences \& RC, Mukka, Surathkal,

Mangalore-575003, Karnataka, India.

E-mail: pnachar2012@gmail.com

DOI: $10.14260 /$ jemds/2020/628

How to Cite This Article:

Ranjan A, Achar PN, Khan P, et al. Pattern of ocular morbidity in school going children. J Evolution Med Dent Sci 2020; 9(39):2870-2873, DOI:

10.14260/jemds/2020/628

Submission 07-04-2020,

Peer Review 17-08-2020,

Acceptance 24-08-2020,

Published 28-09-2020.

Copyright (C) 2020 Alok Ranjan et al. This is an open access article distributed under Creative Commons Attribution License [Attribution 4.0 International (CC BY 4.0)] 


\section{BACKGROUND}

Blindness is one of the significant social problems in India. ${ }^{1}$ In India total child population in 2010 was 345 million and number of blind children was $2,80,000$. The prevalence of blindness declined to $1.4 \%$ than previous data after vision $2020 .^{2}$ Childhood eye morbidity is defined as "Any eye disease or condition that requires ophthalmic care and treatment which if untreated can often progress to serious and sight threatening disease." 3 Ocular morbidities include refractive errors, vitamin A deficiency, conjunctivitis, trachoma, ocular trauma, blepharitis, stye, chalazion, cataract, squint, corneal diseases, congenital disorder, colour blindness, pterygium and posterior segment pathologies.

According to the pattern of ocular diseases varies in different part of the world and is influenced by racial, geographic, socioeconomic and cultural factors. The rate of infection and complication are influenced by a number of socio-economic and socio-cultural factors and season. Children do not complain of defective vision and may not even be aware of their problem. They adjust to the poor eye sight by sitting near the blackboard, holding the books closer to their eyes, squeezing the eyes and even avoiding work requiring visual concentration. This warrants early detection and treatment to prevent permanent disability. Children in the school-going age group (6-16 years) represent $25 \%$ of the population in the developing countries. They offer significantly representative material for these studies as they fall best in the preventable blindness age group, are a controlled population i.e. they belong to a certain age group and are easily accessible and schools are the best forum for imparting health education to the children. Schools are also one of the best centres for effectively implementing the comprehensive eye healthcare programme. ${ }^{4}$

A study of the pattern of ocular diseases in children is very important because while some eye conditions are just causes of ocular morbidity, others invariably lead to blindness. It is estimated that the cumulative number of blind - person-years worldwide due to childhood blindness ranks second only after the cumulative number of blind-person-years due to cataract blindness. ${ }^{5}$ Considering the fact that $30 \%$ of India's blind lose their eyesight before the age of 20 years and many of them are under five when they become blind, the importance of early detection and treatment of ocular disease and visual impairment among young children is obvious. ${ }^{6}$

There are data available on prevalence of ocular morbidity in school going children in developing countries. Many initiatives have been taken at our tertiary care centre for e.g. school to school screening and counselling, school health programme etc. We actively participate under various programs of vision 2020 and NPCB. With this background, the present study was conducted with the objective to determine the pattern and prevalence of ocular morbidity among the children attending school in the district of Kanpur (U.P.) and also compares the prevalence of ocular diseases in children of government schools and private schools, rural and urban locality.

We wanted to study the pattern of ocular morbidity among school going children in the age group of $6-16$ yrs. in public schools in urban and rural areas of Kanpur city.

\section{METHODS}

A cross-sectional prospective study was done among 2105 school going children (rural - 956 and urban -1149) of age 616 years, in rural and urban areas of Kanpur city ovae period of 1 year. The students were screened with the help of Snellen's, E-chart, Ishihara chart. Any child having visual acuity of $6 / 9$ or worse improving with the pinhole was examined for refractive error. Any child of vision $\leq 6 / 12$ not improving with pin hole was undergone retinoscopy followed by subjective refraction at LLRH hospital, Kanpur. Simple corneal light reflex, ocular movements, cover- uncover, test was done for detection of squint. A comprehensive ocular examination was done with the help of Torch light, Slit lamp and 90D and direct ophthalmoscope to examine the anterior and posterior segment pathologies.

All the children between 6-16 yrs. of age in the selected schools was examined for ocular morbidity. Prevalence of ocular morbidity like refractive errors, vitamin A deficiency, trachoma, ocular trauma, blepharitis, stye, conjunctivitis, chalazion, cataract, squint, corneal diseases, congenital disorder, colour blindness, pterygium, amblyopia and posterior segment pathologies.

\section{Statistical Analysis}

Data was analysed using Statistical Package for the Social Sciences (SPSS) Version 19. Comparison of the discrete variables were evaluated and significance was shown as $p$ value $(\mathrm{p}<0.05)$ by using Fischer's Exact Test.

\section{RESULTS}

\begin{tabular}{|cccc|}
\hline $\begin{array}{c}\text { Type of Ocular } \\
\text { Morbidity }\end{array}$ & $\begin{array}{c}\text { Urban Area } \\
(\mathbf{n = 1 1 4 9 )}\end{array}$ & $\begin{array}{c}\text { Rural Area } \\
(\mathbf{n = 9 5 6 )}\end{array}$ & P Value \\
Refractive errors & $301(26.19 \%)$ & $152(15.9 \%)$ & $<0.0001$ \\
squint & $32(2.78 \%)$ & $35(3.66 \%)$ & $=0.3190$ \\
Vitamin A deficiency & $22(1.91 \%)$ & $123(12.86 \%)$ & $<0.0001$ \\
Blepharitis & $21(1.83 \%)$ & $52(5.43 \%)$ & $<0.0001$ \\
Stye & $8(0.70 \%)$ & $23(2.40 \%)$ & $=0.0017$ \\
Colour blindness & $14(1.21 \%)$ & $11(1.15 \%)$ & $=1.000$ \\
Ptosis & $4(0.35 \%)$ & $16(1.67 \%)$ & $=0.0025$ \\
\hline Table 1. Prevalence of Different Types of Ocular Morbidity in School \\
Going Children Aged 6-16 Years in Rural and Urban Areas \\
\hline
\end{tabular}

\begin{tabular}{|c|c|c|}
\hline $\begin{array}{l}\text { Type of Ocular } \\
\text { Morbidity }\end{array}$ & $\begin{array}{c}\text { Males } \\
(n=595)\end{array}$ & $\begin{array}{l}\text { Females } \\
(n=361)\end{array}$ \\
\hline Refractive errors & $97(16.03 \%)$ & $55(15.23 \%)$ \\
\hline squint & $22(3.69 \%)$ & $13(3.60 \%)$ \\
\hline Vitamin A deficiency & $73(12.26 \%)$ & $50(13.85 \%)$ \\
\hline Blepharitis & $37(6.21 \%)$ & $15(4.15 \%)$ \\
\hline Stye & $16(2.68 \%)$ & $7(1.93 \%)$ \\
\hline Colour blindness & $8(1.34 \%)$ & $3(2.21 \%)$ \\
\hline Ptosis & $8(1.34 \%)$ & $8(0.83 \%)$ \\
\hline $\begin{array}{l}\text { Posterior segment } \\
\text { pathologies }\end{array}$ & $2(0.33 \%)$ & 0 \\
\hline
\end{tabular}

The overall prevalence of ocular morbidity was found to be 81 $\%$. Overall Prevalence of ocular morbidity in school going children age 6 - 16 years in rural and urban areas was 38.81 $\%$. In urban area the most common refractive error was myopia (13.23 \%) followed by compound astigmatism (5.74 $\%$ ), simple astigmatism (3.65\%), hypermetropia and least mixed astigmatism $(0.35 \%)$. The prevalence of refractive error in rural area was $15.9 \%$ in which myopia (7.32\%) 
followed by compound astigmatism (3.66 \%), simple astigmatism (2.56\%), hypermetropia (2.24\%) and mixed astigmatism $(0.10 \%)$. In study prevalence of ocular morbidity in students was $11.58 \%$. The prevalence was more in Municipal Corporation School (7.35 \%) while in Private English medium school it was $4.24 \%$ amongst total Students. ${ }^{7}$

\begin{tabular}{|ccc|}
\hline $\begin{array}{c}\text { Type of Ocular } \\
\text { Morbidity }\end{array}$ & $\begin{array}{c}\text { Males } \\
(\mathbf{n = 6 9 6 )}\end{array}$ & $\begin{array}{c}\text { Females } \\
(\mathbf{n = 4 5 3 )}\end{array}$ \\
Refractive errors & $170(24.42 \%)$ & $131(28.91 \%)$ \\
\hline squint & $16(2.29 \%)$ & $16(3.53 \%)$ \\
Vitamin A deficiency & $14(2.01 \%)$ & $8(1.76 \%)$ \\
Blepharitis & $13(1.86 \%)$ & $8(1.76 \%)$ \\
Stye & $4(0.57 \%)$ & $4(0.88 \%)$ \\
Colour blindness & $13(1.86 \%)$ & $1(0.22 \%)$ \\
Ptosis & $3(0.43 \%)$ & $1(0.22 \%)$ \\
Posterior segment & 0 & $1(0.22 \%)$ \\
pathologies & $233(33.47 \%)$ & $170(37.2 \%)$ \\
\hline \multicolumn{2}{|c|}{ Table 3. Sex Wise Distribution of Ocular Morbidity } \\
& In Urban School Children \\
\hline
\end{tabular}

\begin{tabular}{|ccc|}
\hline $\begin{array}{c}\text { Types of Refractive } \\
\text { Error }\end{array}$ & No. & $\begin{array}{c}\text { \% Out of Total } \\
\text { (Prevalence) }\end{array}$ \\
Myopia & 152 & 13.23 \\
Hypermetropia & 37 & 3.22 \\
Simple astigmatism & 42 & 3.65 \\
Compound astigmatism & 66 & 5.74 \\
Mixed astigmatism & 4 & 0.35 \\
Total & $\mathbf{3 0 1}$ & $\mathbf{2 6 . 1 9}$ \\
\hline Table 4. Prevalence of Types of Refractive Error \\
In Urban Population (n=1149) \\
\hline
\end{tabular}

\begin{tabular}{|ccc|}
\hline Types of Refractive Error & No. & \% Out of Total (Prevalence) \\
Myopia & 70 & 7.32 \\
Hypermetropia & 21 & 2.24 \\
Simple astigmatism & 25 & 2.56 \\
Compound astigmatism & 35 & 3.66 \\
Mixed astigmatism & 1 & 0.10 \\
Total & 152 & 15.9 \\
\hline Table 5. Prevalence of Types of Refractive Error \\
In Rural Population (n=956) \\
\hline
\end{tabular}

\section{DISCUSSION}

The present prospective study was done among a total of 2105 school going children of age 6 - 16 years in rural and urban areas of Kanpur city to determine the prevalence of ocular morbidity in school going children along with its correlation with age and sex.

From this study it was seen that the overall prevalence of ocular morbidity in the school children ages 6-16 yrs. of rural and urban areas of Kanpur city was $38.82 \%$ i.e. 817 out of 2105. In rural area 414 and in urban area 403 were diagnosed as ocular morbidity. Thus, the prevalence in rural area 43.30 $\%$ was much higher than that of urban area $35.07 \%$ and it was statistically extremely significance $\mathrm{p}=0.0001$.

Various other studies in India showed higher prevalence like Rajesh Kumar et al. ${ }^{8}$ In their study observe that the prevalence of ocular morbidity was $24.6 \%$. Madhu Gupta, Bhupinder P Gupta et $\mathrm{al}^{4}$ observed that the overall prevalence of ocular morbidity among school children of age 6-16 years was $31.6 \%$. Higher prevalence of ocular morbidity was seen in the study at Kathmandu valley, Nepal by Rajesh Kishore Shrestha, et al ${ }^{11}$ as $34.2 \%$ in age group of 5-16 years. But lower prevalence of $19.9 \%$ was seen by Ayanniyi A et al. ${ }^{12}$ Study done on 277 pupils at Ilorin. Similar results were also seen in study by Deshpande Jayant D et al ${ }^{10}$ showing $27.65 \%$ as ocular morbidity.

\section{Refractive Error}

Among ocular morbidity refractive error was the most common cause in both the rural and urban children. The prevalence of refractive error in urban children $(26.19 \%)$ was much higher and statistically significant $(\mathrm{p}<0.0001)$ than the rural children (15.9\%). Females were affected more in urban areas along with higher percentage of refractive error seen in age group 11-16 years.

In refractive errors of urban school children myopia was most common (13.23 \%) followed by compound astigmatism (5.74\%), simple astigmatism (3.65\%), hypermetropia (3.22 $\%$ ) with least of mixed astigmatism (0.35\%). The same pattern followed in rural children also with myopia being the most common (7.32 \%) followed by compound astigmatism (3.66 $\%)$ and mixed astigmatism being the least one (0.10\%).

Hypermetropia was more common in age group 6-10 yrs. Similar results was seen in study conducted by Naik Ret al ${ }^{13}$ who found Refractive errors (7.57 \%) constitute the major cause of ocular morbidity, myopia being the commonest refractive error. In study done by Ghosh S, Mukhopadhyay U et al,14 Refractive error was seen in $14.7 \%$. Myopia and hypermetropia was present in 307 (11.9\%) and 65 (2.5 $\%)$ children, respectively.

A study by Dandona $\mathrm{R}$, et $\mathrm{al}^{15}$ found that refractive error was the cause in $61 \%$ of the total eyes with visual impairment. A gradual shift to lesser positive values as age progresses was noted. Myopia was present in $4.1 \%$ of the total value. Hypermetropia in $0.8 \%$ of the total. $70 \%$ of the children benefited from wearing spectacles. The results of the present study were quite similar to the study by Rajesh Kishore Shrestha, et al ${ }^{11}$ that showed refractive error being the most common ocular morbidity $(21.8 \%)$.

Simple myopia (10.1\%) was the commonest followed by compound astigmatism (4.6\%) and the least common was mixed astigmatism $(0.3 \%)$. Pavithra MB et al ${ }^{16}$ found that prevalence of refractive error in age 7-15 years of school children was $7.03 \%$. Myopia being the most common (4.4\%), followed by astigmatism (1.6\%) and hypermetropia (1.03\%).

\section{CONCLUSIONS}

Refractive error was the most common ocular morbidity in both urban and rural areas, but Vitamin A deficiency and blepharitis were more common in rural areas. In rural areas malnutrition seems to be the major cause of ocular morbidity while more use of gadgets and less outdoor activity seems to play vital role in urban areas.

Improving the diet, hygiene and education in rural areas may help in decreasing the overall ocular morbidity in rural areas. Whereas, in urban areas increasing outdoor activities, proper reading habits and decrease in gadgets use may help in decreasing ocular morbidities in these areas.

Proper health education to parents as well as regular eye check-ups are essential to prevent and early diagnose ocular disease in children.

Financial or Other Competing Interests: None. 


\section{REFERENCES}

[1] Desai S, Desai R, Desai NC, et al. School eye health appraisal. Indian J Opthalmol 1989;37(4):173-5.

[2] Chandna A, Gilbert C. When your eye patient is a child. Community Eye Health 2010;23(72):1-3.

[3] VISION 2020: the right to sight-how does vision 2020 work? http://www.vision2020.org

[4] Gupta M, Gupta BP, Chauhan A, et al. Ocular morbidity prevalence among school children in Shimla, Himanchal, North India. Indian J Ophthalmol 2009;57(2):133-8.

[5] Foster A. Worldwide blindness: increasing but avoidable. Semin Ophthalmol 1993;8(3):166-70.

[6] Jha KN. Baseline ophthalmic data of school children aged 15 years or younger in Leh, Jammu and Kashmir, India. J Clin Diag Res 2008;4(2):1186-90.

[7] Kumar P, Pore P, Dixit AK, et al. Demographic profile of ocular morbidity in school children in India. Sch J App Med Sci 2013;1(5):645-52.

[8] Kumar R, Dabas P, Mehra M, et al. Ocular morbidity amongst primary school children in Delhi. Health Population 2007;30(3):222-9.

[9] Mahapatro S, Das M, Padhy G, et al. Prevalence of ocular disorders in school children in rural area surrounding Bhubaneswar. Indian J Community Med 2010;6(1):502-4.
[10] Deshpande JD, Malathi K. Prevalence of ocular morbidities among school children in rural area of North Maharashtra in India. National J Community Med 2011;2(2):302-4.

[11] Shrestha RK, Joshi MR, Ghising R, et al. Ocular morbidity among children studying in private schools of Kathmandu valley: a prospective cross sectional study. Nepal Med Coll J 2006;8(1):43-6.

[12] Ayanniyi A, Mahmoud AO, Olatunji FO. Causes and prevalence of ocular morbidity among primary school children in Ilorin, Nigeria. Niger J Clin Pract 2010;13(3):248-53.

[13] Naik R, Gandhi J, Shah N. Prevalence of ocular morbidity among school going children (6-15years). Sch J App Med Sci 2013;1(6):848-51.

[14] Ghosh S, Mukhopadhyay U, Maji D, et al. Visual impairment in urban school children of low-income families in Kolkata, India. Indian J Public Health 2012;56(2):163-7.

[15] Dandona R, Dandona L. Refractive error blindness. Bulletin of the World Health Organisation 2001;79(3):237-43.

[16] Pavithra MB, Maheshwaran R, Sujatha RMA. A Study on the prevalence of refractive errors among school children of 7-15 years of age group in the field practice areas of a medical college in Bangalore. Int J Med Sci Public Health 2013;2(3):641-5. 